\title{
Structural Fire Design of Timber Structures According to Eurocode 5
}

\author{
JÜRGEN KÖNIG \\ SP Trätek/Wood Technology \\ Box 5609 \\ SE-114 86 Stockholm, Sweden
}

\begin{abstract}
This paper gives an overview of EN 1995-1-2 dealing with structural fire design of timber structures. This European standard is part of the Eurocodes system, to be implemented in the European Union and EFTA countries. The paper describes the main topics of the code and focuses on changes introduced during the revision of its forerunner ENV 1995-1-2. Charring and the effect of applied fire protective claddings are dealt with in a consistent way. Alternative rules for strength and stiffness parameters are discussed. New improved, however still incomplete, rules for connections can easily be extended when new knowledge becomes available. The modified components additive method for the verification of the separating function of wall and floor assemblies takes into account both properties and the position of layers. For the application of advanced calculation methods, effective material properties are given: thermal properties, taking into account effects of char cracking and char recession, and thermo-mechanical properties taking into account influence of elevated temperature and moisture on strength and stiffness.
\end{abstract}

KEYWORDS: timber, structures, structural design, fire, fire resistance, charring, protection of wood, connections, calculations, codes

\section{INTRODUCTION}

In 1994, the first version of the Fire Part of Eurocode 5 was published as a European prestandard ENV 1995-1-2 [1] to be implemented for experimental application in the Member States of the European Union and EFTA. For the time being, the complete set of Eurocodes, comprising 58 Parts, is being revised and transferred into European Standards (EN). The last Eurocode Parts are expected to be finalised by the end of 2006. The new Eurocode 5 Fire Part, EN 1995-1-2 [2], was made available by CEN (European Committee for Standardization) in November 2004 together with the two other Parts of Eurocode 5, EN 1995-1-1 [3], dealing with common rules and rules for buildings, and EN 1995-2 [4] with design rules for bridges. It is expected to be completely implemented in Member States (Austria, Belgium, Cyprus, Czech Republic, Denmark, Estonia, Finland, France, Germany, Greece, Hungary, Iceland, Ireland, Italy, Latvia, Lithuania, Luxemburg, Malta, Netherlands, Norway, Poland, Portugal, Slovakia, Slovenia, Spain, Sweden, Switzerland and United Kingdom) and that conflicting National standards are withdrawn at the latest by March 2010. In general, the Eurocodes will be the main reference documents for product standards and European Technical Approvals for CEmarking construction products in the European market place [5]. Other Eurocode Fire Parts deal with concrete, steel, masonry and composite steel and concrete structures.

ENV 1995-1-2 [1] was a great step forward to common European structural fire design rules for timber structures. Previous National rules, in those Member States where such rules existed, were of different complexity, depending on the level of development in the 
field of fire design of timber structures achieved in respective country. Also design rules varied considerably, for example the charring rates given in National codes, or the way of dealing with material strength in fire. There was no common safety philosophy; sometimes safety factors and/or the effects of elevated temperature on strength and stiffness properties where implicitly included in the charring rates; in other cases one or both of them were given separately. In ENV 1995-1-2 [1], there was a serious attempt to strictly distinguish between material properties and safety factors and to present methods of different levels of complexity.

This paper describes the main topics of the code and focuses on changes introduced during the revision of its forerunner ENV 1995-1-2 [1]. For a more comprehensive presentation of the background and a list of references, see [6].

\section{APPLICATION OF EN 1995-1-2}

In general, the essential requirement of safety in the case of fire, given in the Construction Products Directive, can be satisfied by following different strategies. One strategy is to apply nominal fire scenarios such as the standard fire scenario; another is the application of natural fire scenarios, e.g., given by parametric fire curves. These may include aspects of active measures of fire safety, see [7]. Since our knowledge on the performance of timber structures in natural fires is still limited, the rules given in EN 1995-1-2 mainly refer to standard fire exposure. The requirements with respect to fire resistance, normally given by National Building Regulations, are expected to include aspects of building height, occupancy, alarm, automatic or manual fire suppression etc.

Since Eurocode Parts are not self-containing documents, the user will need various other Eurocode Parts, such as EN 1990 [8], EN 1991-1-2 [7], EN 1995-1-1 [9], and various product standards. The intention is that design manuals and design aids will be produced and made available to the designer.

The various material related Eurocode Fire Parts follow the same layout. Section 1 (scope, normative references, assumptions, definitions and symbols) and Section 2 (basis of design) are identical with those of the other Fire Parts, with the exception of material specific items.

\section{BASIS OF DESIGN}

\section{General}

Section 2 of the material related Fire Parts of the Eurocodes gives rules on requirements, actions, design values of material properties and resistances (that is how design values are established from characteristic values) and verification methods.

\section{Requirements}

Here the well-known acceptance criteria are given, dealing with load-bearing function (R), integrity (E) and insulation (I). Criteria are also given for natural fires scenarios given by parametric fire curves as defined in EN 1991-1-2 [7]. The load-bearing function must be maintained during the complete duration of the fire including the decay phase, or a specified period of time. The insulation criteria are given as the maximum permissible increases in the average and peak temperatures of 140 and $180 \mathrm{~K}$ respectively as for standard fire exposure, while it is 200 and $240 \mathrm{~K}$ during the decay phase. The 
requirement for the heating phase was chosen although it seems illogical, since it is covered by the requirement during the decay phase. It should be noted that the 140/180 K criterion for standard fire exposure had been chosen in order to include a safety margin that takes into account the temperature rise that would occur during the decay phase in a natural fire scenario, but is not explicitly taken into account in the standard fire scenario.

\section{Design Values}

The design values of strength properties (and correspondingly for stiffness properties) of timber are given as

$$
f_{\mathrm{d}, \mathrm{fi}}=k_{\text {mod,fi }} \frac{f_{20}}{\gamma_{\mathrm{M}, \mathrm{fi}}}
$$

with

$$
f_{20}=k_{\mathrm{fi}} f_{\mathrm{k}}
$$

that is the design strength in the fire situation, $f_{\mathrm{d}, \mathrm{fi}}$, is based on the $20 \%$ fractile of the cold strength properties, $f_{20}$. This fractile can be determined by multiplying the characteristic property (which is the $5 \%$ fractile) by a factor $k_{\mathrm{fi}}$ that is dependant on the coefficient of variation of the material. For example, for solid timber $k_{\mathrm{fi}}=1.25$ and for glued laminated timber $k_{\mathrm{fi}}=1.15$. The recommended value of the partial factor in the fire situation $\gamma_{\mathrm{M}, \mathrm{fi}}$ is unity and was chosen in order to get harmonisation of different material related Eurocode Fire Parts. The modification factor $k_{\text {mod,fi }}$ gives the reduction of the strength (or stiffness) properties due to elevated temperature in (parts of) the residual cross-section. This modification factor replaces the corresponding modification factor $k_{\text {mod }}$ in cold design to take account of influences of load duration and moisture.

\section{Verification Methods}

EN 1990 [8] states, as a principle, that the structural analysis, among other things, shall consider models for the temperature evolution within the structure as well as models for the mechanical behaviour of the structure at elevated temperature. The application rule satisfying this principle says that the required performance should be verified by either global analysis, analysis of sub-assemblies or member analysis. Traditionally, member analysis corresponds to design by testing performing full-scale furnace tests of members (beams, columns, floors, walls). For timber structures member analysis is sufficient, since thermal elongations of timber members - due to the large temperature gradient across the cross-section and a sufficiently large cold core in the timber member - are negligible and thus only have negligible influence on the structural system. This structural performance is in contrast to other structural materials such as steel and concrete. A global analysis will often offer favourable alternatives, e.g., in the simple case that premature failure of structural elements, e.g., an internal non-separating wall, will be compensated by alternative load paths in redundant structural systems, such that structural collapse of the building is prevented. In general, the Eurocode Fire Parts allow design by testing or by a combination of testing and calculations. 


\section{CHARRING}

Charring of timber, reducing the cross-section of a timber member, is normally the dominating effect of a fire exposure on the mechanical resistance of timber members. The clauses dealing with charring have undergone considerable revision compared to ENV 1995-1-2 [1]. , The charring rate observed under one-dimensional heat transfer conditions in a semi-infinite timber slab under standard fire exposure, $\beta_{0}$, has been chosen as the basic value, see Fig. 1a. One-dimensional charring also takes place in sufficiently large cross-sections, such as glued laminated beams, see Fig. $1 \mathrm{~b}$. When this char depth $d_{\text {char }, 0}$ is applied, the roundings at corners must be taken into account. In order to simplify the calculation of cross-sectional properties (area, section modulus and second moment of area) by assuming an equivalent rectangular residual cross-section (see Fig. 1b, notional charring rates $\beta_{\mathrm{n}}$ are derived such that they implicitly include the effect of corner roundings and approximately give the same results. For the application of onedimensional charring rates instead of notional charring rates minimum requirements regarding the width of the cross-section apply.

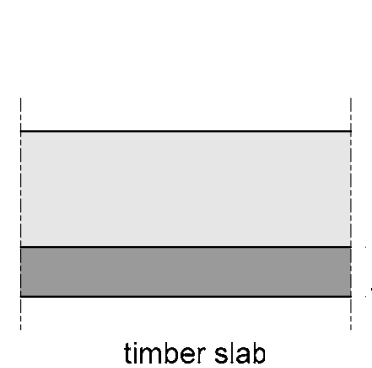

a)

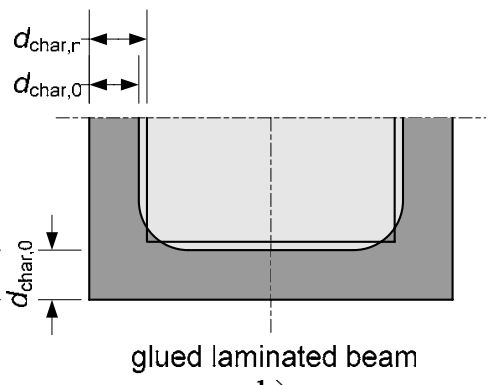

b)

Fig. 1. Charring of timber slab (a) and glued laminated beam (b).

For softwoods, the (one-dimensional) charring rate of Eurocode 5 is given as independent of species and densities. This is in contrast to e.g., North American experience where different species exhibit considerable influence on the charring rate. For the time being, in Europe these species do not play a major roll in the market place, however increased trade may change this. When Eurocode 5 is used outside Europe, special attention should be paid to species and density.

The charring rules are reasonably adequate for rectangular cross-sections that are exposed on three or four sides, or slabs exposed on one side. For simplicity, EN 1995-1-2 abstains from giving minimum sizes of residual cross-sections for the validity of the charring rates given in the standard, although it is known that the charring rate will increase when the residual thickness is under a critical value. The reason is that this would happen beyond the stage of mechanical failure. For light timber members in floor or wall assemblies with glass or rock fibre filled cavities, special rules are given, see Fig. 2. Although the sides of the members facing the cavity are protected by insulation, this protection is incomplete due to two-dimensional heat transfer giving rise to extensive charring at corners. Other cases of partial protection, e.g., as shown in Fig. 3 showing a timber stud and cavity partially filled with insulation, cannot be dealt with using the simplified charring rules of EN 1995-1-2. 


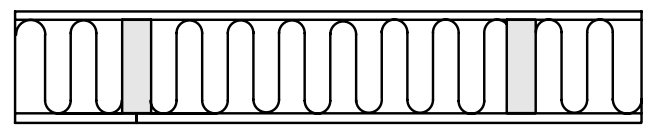

管

a)

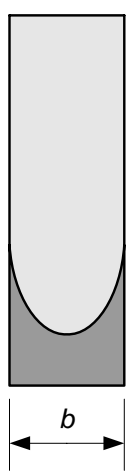

b)

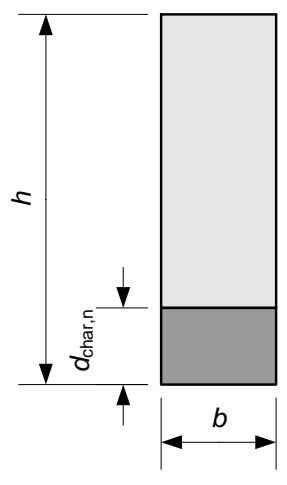

c)

Fig. 2. Cross-section of timber frame assembly (a) and charring of timber member with real (b) and equivalent (notional) residual cross-section (c).

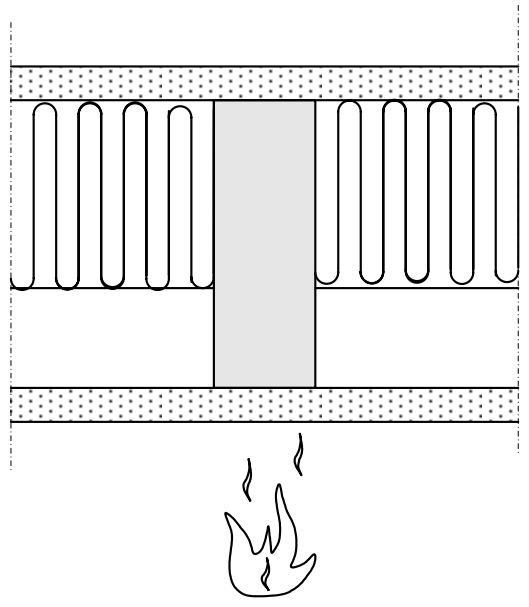

Fig. 3. Example of partially protected timber member.

The rules on protected timber have undergone considerable changes. They now take into account the fact that different charring rates should be applied during different phases of the fire exposure, see Figs. 4 and 5. The code gives factors $k_{2}$ and $k_{3}$ for multiplication of the charring rates. When the timber is protected by a cladding - e.g., wood-based panel or gypsum plasterboard - the start of charring is delayed until time $t_{\mathrm{ch}}$. If the cladding falls off at that time (this would normally occur when the cladding is a wood-based panel), then charring is assumed to take place at the double rate (compared to charring of initially unprotected surfaces) as long as the char depth is not greater than $25 \mathrm{~mm}\left(k_{3}=2\right)$. Finally, beyond that char depth, charring continues with the rate valid for initially unprotected timber. When the protection remains in place some time after the start of charring, e.g., in the case of gypsum plasterboard type F (with improved core cohesion) or calcium silicate board, a phase with a reduced charring rate follows after the onset of charring $\left(k_{2}<1\right)$. For failure of the protection two failure modes apply: thermal degradation of the protection or pull-out failure of fasteners due to charring of the timber behind the protection. With respect to pull-out failure of fasteners, a nominal minimum penetration length into unburned wood of $10 \mathrm{~mm}$ should be applied. Unfortunately, since 
no generic data were available, no times of failure due to thermal degradation are given for type F plasterboard. These must be determined by testing according to ENV 13381-7 [10]. The code also gives some rules for timber protected by batt-type rock fibre insulation.

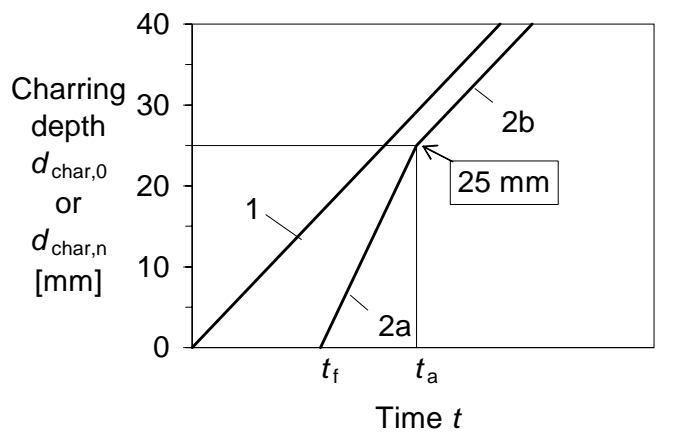

Fig. 4. Charring for early failure of protection: 1 unprotected timber; 2a, 2b |protected timber with simultaneous start of charring and failure of protection at $t=t_{\mathrm{ch}}=t_{\mathrm{f}}$.

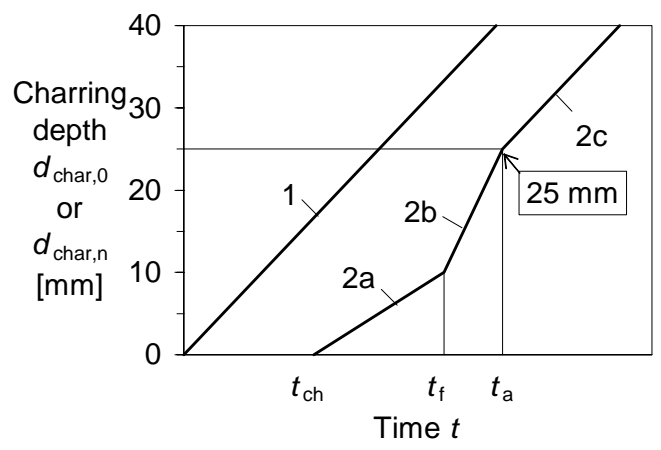

Fig. 5. Charring for delayed failure of protection: 1 unprotected timber; 2a-c protected timber with start of charring at $\mathrm{t}=\mathrm{t}_{c h}$ and failure of protection at $\mathrm{t}=\mathrm{t}_{\mathrm{f}}$.

\section{CROSS-SECTIONAL PROPERTIES}

For timber members such as beams and columns EN 1995-1-1 gives two alternative methods for the determination of cross-sectional properties for the load-bearing capacity of beams and columns. The recommended method is the reduced cross-section method. It is easiest to use and has the widest scope of application. This method, permitting the designer to use an effective residual cross-section with "cold" strength and stiffness properties (with $k_{\text {mod,fi }}=1$ inserted in Eq. 1), takes into account the reduction of these properties in the heat affected zones by removing a further $7 \mathrm{~mm}$ thick layer from the residual cross-section, see Fig. 6. The removal of the $7 \mathrm{~mm}$ layer also allows for reductions in mechanical properties as the temperature rises in the first 20 minutes, as well as temperatures rising beneath any protective claddings prior to charring. 


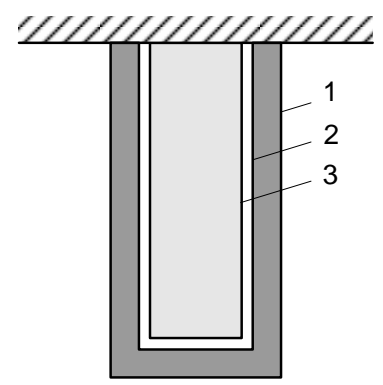

Fig. 6. Determination of effective residual cross-section with borders of (1) initial, (2) residual, and (3) effective residual cross-section.

The alternative reduced properties method gives values of $k_{\text {mod,fi }}$ for compressive, tensile and bending strengths as well as the modulus of elasticity of members to be inserted in Eq. 1. The calculated mechanical resistance is greater than obtained by the reduced crosssection method. Unfortunately, this method has a several drawbacks, including the following:

- the gradual strength reduction during the first 20 minutes or until start of charring of protected members is not taken into account;

- $\quad$ no modification factors are given for shear strength;

- $\quad$ although the method seems more complex and is pretended to be more precise than the reduced cross-section method, it cannot be verified using advanced methods, see below; and

- the method is only valid for three- and four-sided exposure and cannot be used for timber slabs.

It should be noted that these two alternative methods don't apply to timber frame members in wall and floor assemblies with completely filled cavities.

\section{RULES FOR WALL AND FLOOR ASSEMBLIES}

\section{Separating Function}

The simple components additive method that was given in ENV 1995-1-2 [1] has been modified by combining it with a method that has been used in Sweden since 1995, also considering new test results. The total fire resistance, taken as the sum of the contributions from the different layers of the assembly (claddings, void or insulated cavities) considering different heat transfer paths, see Fig. 7, is

$t_{\text {ins }}=\sum_{\mathrm{i}} t_{\text {ins }, 0, \mathrm{i}} k_{\text {pos }} k_{\mathrm{j}}$

where $t_{\text {ins, }, 0, \mathrm{i}}$ is the inherent insulation period of layer "i" in minutes, $k_{\mathrm{pos}}$ is a position coefficient and $k_{\mathrm{j}}$ is a coefficient for the influence of joints in claddings not backed with a battens or structural element. 


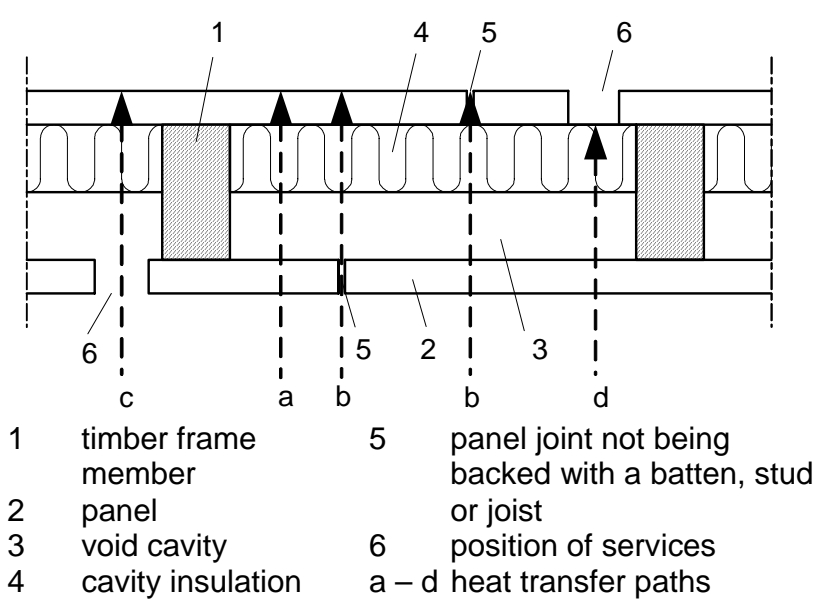

Fig. 7. Heat transfer paths through a separating construction.

\section{Load-bearing Function}

The method, given in an informative annex of the code, is valid for timber frame assemblies with cavity insulation, see Fig. 2a. Notional charring rates are given for the determination of an equivalent (notional) residual cross-section of the timber member as shown above, see Fig. $2 b$ and c. The effect of fire protective claddings follow the presentation of Figs. 4 and 5, however without the stabilising effect of the char layer being built-up, that is a uniform value of the charring rate is given for the stage after failure of the protection since the effect of rapidly increasing corner roundings is dominating the charring behaviour. Modification factors $k_{\text {mod,fi }}$ that are different from those for beams and columns as shown in previous section are given for insertion in Eq. 1 and determination of the mechanical strength and stiffness parameters of the crosssection.

Unfortunately, the char model given for timber members in assemblies with void cavities is coarse and unsatisfactory. Although advanced models exist, these have not been used to derive simple calculation methods that are consistent with the design philosophy of Eurocode 5.

\section{CONNECTIONS}

The design rules for connections have been improved considerably compared to previous rules given in ENV 1995-1-2 [1]. The rules apply to laterally loaded symmetrical threemember connections in shear, see Fig. 8. For connections with screws, the design rules also include axially loaded fasteners.

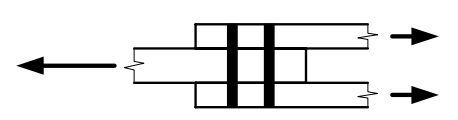

Fig. 8. Symmetrical three-member connection.

Unprotected connections in shear that comply with the requirements at ambient temperature according to EN 1995-1-1 are deemed to satisfy fire resistance durations of 
15 minutes (e.g., nails, screws, bolts) or 20 min (dowels). When a fire resistance of 30 minutes is required, the dimensions of the timber members (and correspondingly also the length of fasteners) should be increased, except for bolted connections, since the bolt heads give rise to increased heat flux into the timber members. For connections with bolts or any other of the above mentioned fasteners, for fire resistances up to 60 minutes, the connection should be protected by an additional layer of timber, wood-based panel or gypsum plasterboard. Alternatively, the fasteners should be protected by bonded-in plugs.

An alternative strategy of increasing fire resistance is to reduce the load (degree of utility). The code gives following expression between the relative load-bearing capacity $\eta$ and time to failure $t_{\mathrm{d}, \mathrm{fi}}$ :

$\eta=\mathrm{e}^{-k t_{\mathrm{d}, \mathrm{fi}}}$

where $k$ is dependent on the fastener type, see examples shown in Fig. 9. The relationships are valid for exposure times up to 20, 30 or 40 minutes, respectively. For greater fire resistances the dimensions of the timber should be increased or separate fire protection should be applied, see above. Recent results of fire tests with dowelled connections with internal steel plates [8] show that connections with multiple rows of fasteners and more than one slotted-in steel plate exhibit greater fire resistance than shown in Fig. 9, whereas there is a good agreement with the rules for increased timber dimensions or applied fire protective boards. Since the expressions shown in Fig. 9 were based on fire tests with three-member connections (that is in the case of steel-to-wood connections with only one slotted in steel plate) with two to four rows of fasteners parallel to grain, two-parameter exponential functions would be more adequate to describe the relationship between load-bearing capacity and time.

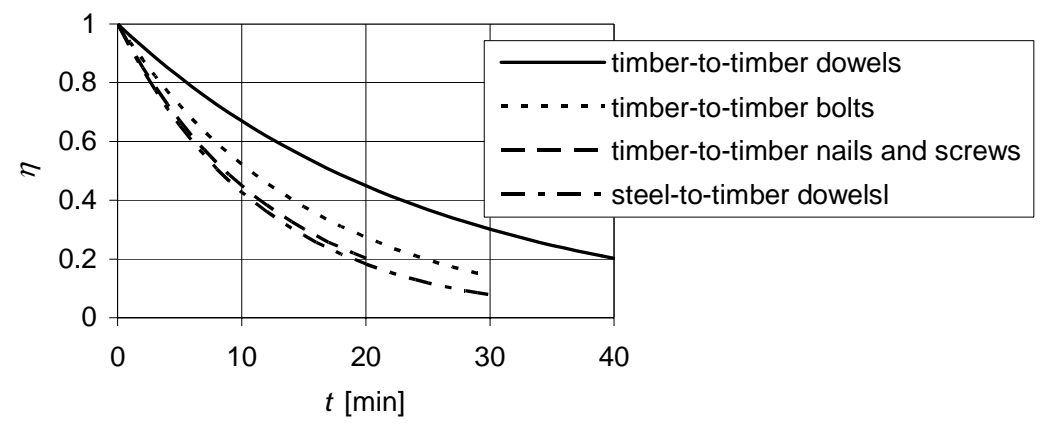

Fig. 9. Relationships between relative lateral load-bearing capacity and time to failure for unprotected connections.

\section{ADVANCED CALCULATION METHODS}

While the main content of EN 1995-1-2 are more or less simplified rules in order to take into account the effect of temperature evolution within the structure, an informative annex to EN 1995-1-2 also gives guidance to the use of advanced calculation methods, e.g., finite element methods for thermal and structural analysis of timber structures. For thermal analysis, effective thermal properties of timber are given, taking into account the influence of char cracking and char surface recession. These thermal properties should 
not be used for other than standard fire exposure. The thermo-mechanical properties, strength (tension, compression, shear) and stiffness properties (modulus of elasticity for tension and compression), also include transient effects of combined moisture and elevated temperature around $100^{\circ} \mathrm{C}$, including the effect of moisture accumulation in the residual cross-section and mechano-sorptive creep when the water is vaporised.

\section{NATIONAL CHOICES}

EN 1995-1-2 allows the possibility of a National choice in the following cases:

- partial factors;

- $\quad$ factors for combinations of actions;

- a method for the determination of cross-sectional strength and stiffness properties, as well as regarding the application of informative annexes (yes or no) dealing with;

- $\quad$ natural fire scenarios;

- $\quad$ advanced calculation methods;

- load-bearing timber frame assemblies with cavity insulation;

- charring of members in assemblies with void cavities;

- analysis of the separating function of wall and floor assemblies; and

- charring of members in wall and floor assemblies with void cavities.

The option of National choices given in the Eurocodes may seem to be an expression of a partial failure in achieving the harmonization of European design rules. Since safetyrelated matters should remain the responsibility of National Regulators, it was decided to introduce so-called Nationally determined parameters (NDP) with recommended values for e.g., partial factors. In other cases, where Member States did not agree on a single design rule or value, alternative rules or values were given, e.g., in EN 1995-1-2 regarding the determination of cross-sectional properties, or design rules were moved to an informative annex, e.g., in EN 1995-1-2 the annex on charring of members in assemblies with void cavities. The other informative annexes of EN 1995-1-2 contain design rules that Member States may or may not wish to apply. The decisions made on the National level will be published in a National annex to each Eurocode Part.

\section{CONCLUDING REMARKS}

In Europe, and hopefully also in other parts of the world, Eurocode 5 will contribute to the increased use of timber in the construction sector, having in mind that several European countries without a long tradition of using timber have lacked design codes for timber structures, and that improved education of designers in the field of timber structures will actualize timber as a competitive alternative to concrete or steel. The Fire Part of Eurocode 5 will increase the insight that timber structures can be designed such that they are safe in the case of fire and regulatory requirements can be satisfied. The Fire Part reflects the fact that comprehensive research has been conducted in several parts of the world. The need of fire testing will be reduced, although there are many gaps in our knowledge still to be filled. 


\section{ACKNOWLEDGEMENTS}

The author, member of the Project Team and chairman of the CEN sub-committee responsible for Eurocode 5, wishes to express his thanks to the members of the Project Team Mario Fontana (CH), Thierry Lamadon (FR), Tuuli Oksanen (FI), Kevin Towler (UK) and Stefan Winter (DE).

\section{REFERENCES}

[1] ENV 1995-1-2:1994, Eurocode 5 - Design of Timber Structures - Part 1-2: General Rules - Structural Fire Design.

[2] EN 1995-1-2:2004, Eurocode 5 - Design of Timber Structures - Part 1-2: General - Structural Fire Design.

[3] EN 1995-1-1:2004, Eurocode 5 - Design of Timber Structures - Part 1-2: General - Common Rules and Rules for Buildings.

[4] EN 1995-1-1:2004, Eurocode 5 - Design of Timber Structures - Part 2: Bridges.

[5] Guidance Paper L - Application and Use of Eurocodes. European Commission, (http://europa.eu.int/comm/enterprise/construction/internal/guidpap/l.htm.), Brussels, 2002.

[6] König J., "Structural Fire Design According to Eurocode 5 - Design rules and their background," Fire and Materials, 29, pp. 147-163, (2005).

[7] EN 1991-1-2:2002, Eurocode 1: Actions on Structures - Part 1-2: General Actions - Actions on Structures Exposed to Fire.

[8] EN 1990:2002, Eurocode - Basis of Structural Design.

[9] EN 1995-1-1:2004, Eurocode 5 - Design of Timber Structures - Part 1-1: General - Common Rules and Rules for Buildings.

[10] ENV 13381-7:2002, Test Methods for Determining the Contribution to the Fire Resistance of Structural Members - Part 7: Applied Protection of Timber Members.

[11] Frangi A, Mischler, A., "Fire Tests on Timber Connections with Dowel-type Fasteners,” Proceedings of CIB W18, Meeting 37, Paper 37-16-1, 2004. 
